\title{
The trends of blended learning in South East Asia
}

\author{
Ford Lumban Gaol ${ }^{1,2} \cdot$ Fonny Hutagalung ${ }^{1,2}$ \\ Published online: 20 February 2020 \\ (C) Springer Science+Business Media, LLC, part of Springer Nature 2020
}

\section{Motivation}

Blended learning which is well-known as cross and mixed-mode learning. It is merging online and face-to-face pedagogical method. The purpose of this kind of learning is to produce combined blended learning atmospheres. Lately, blended learning has blasted as the rapid technology advancement in Information Communication Technology (ICT). It is enabling learning modality of choice of educators worldwide.

As part of this learning model, some parties such as tutors, officers, and representatives in schools, colleges, higher education, governing boards, and ministries are investigating the probabilities of blended learning as a pedagogically sound and valuable technique of broadening access to an education.

In many developed countries, blended learning has become the most favoured model of learning due to a natural consequence of all over the internet and World Wide Web. Online technology has touched education and every aspects of human endeavour in the past 2 centuries. Blended learning has developed as it increased popularity.

However, in developing countries such as in Asean Regions, much research are done. This is becoming one of the challenges since the number of students and teachers in developing countries is bigger than in developed one. Moreover the adoption of technology in developing countries is much greater due to development of latest software, hardware, and capabilities on electronic communications.

It means that blended learning is always changing and the focus of study can be more dynamic.

\section{Aim and contributions}

It is interestingly to note that education systems are continuously changing, with the common reason being the drive to react to the challenges of politic, economy, and

Ford Lumban Gaol

fordlg@gmail.com

1 Bina Nusantara University, Jakarta, Indonesia

2 Department of Education, University of Malaya, Kuala Lumpur, Malaysia 
social that are faced by societies every day (Bakir 2013; Aguilar 2012). In this regard, in order to address the conflicts of multiple technologies education becomes vigorous phenomenon that needs to align with the present trends in society. Hwa et al. (2012); Akkoyunlu and Soylu (2008) observe that the current upsurge in the number of new learners stimulates the need for more effective teaching methods, to create an environment contusive to the most notable trends in computer technology that has revolutionized the school systems.

With the increased use of ICT around the globe, education systems are adapting new technology into the curriculum, to help to meet current demands in the education segment (Lo Bianco 2010). Aguilar (2012) argued that the alignment of technology with education practices is a positive step that has been triggered by issues such as transportation distances and building costs.

Blended learning is the combination of face-to-face and computer-assisted learning into a specific teaching and learning atmosphere (Barnes 2017). Bijeikiene et al. (2011) explained that the term blended has been adopted to refer to integrating ICT into a teaching and learning environment. Blended learning is a combination between face-to-face and online learning aided by ICT platforms (Aguilar 2012). Other scholars, Sharma (2010), mentioned blended learning is a system that unites face-to-face method of teaching technology appropriately. Technology can refer to a wide variety of components including the internet, interactive whiteboards, and language labs among others. Cartner (2009) summarized all of these definitions and describes blended learning in a comprehensive analysis, as a setting in teaching and learning circumstances where there is an effective merger of varied delivery platforms, models of teaching and learning approaches. Blended learning is thus a result of applying a strategic and systematic approach to the application of technology, combined with the best features of face to face interaction between teachers and students. Sharma (2010) mentioned that the definitions of blended learning indicate that there are at least three requirements; more than one delivery mode, instructor-based training methods that are technologically enabled, and traditional teaching approaches which are interactive, rich in content, and facilitated by a teacher. Coryell and Chlup (2007) offered a parallel model; blended learning can have different combinations of these elements: traditional and virtual learning, live and cooperative learning. It is also combining structured and unstructured method of learning, and mixing of either synchronous physical with online formats or asynchronous physical with online formats. The bottom line remains that blended learning has to use two media of instruction. One media represents the traditional methods used in face-toface interaction, and the other media represents a technological mode of instructions of relaying information to the learners. Sharma (2010) concluded his study by arguing that blended learning is a logical response to the development of previous pedagogical tendencies that employed an array of teaching approaches, sometimes aided by novel technology. In sum, the main requirements for blended learning are diverse teaching methods, physical presence of both teacher and students, elements of control such as time and pace, and at least some instruction facilitated by technological platforms for content delivery.

Coryell and Chlup (2007); Creswell (2009); Kintu et al. (2017) found that there is a growing body of literature supporting the use of blended learning in higher 
learning institutions. In a similar vein, scholars have initiated the concept in language teaching as an alternative to the traditional method that was solely based on direct instruction. It is therefore critical to establish an evaluative framework that assesses what blended learning brings to the table for language learning. This study highlights the potentials offered by blended learning to language teaching, to find what benefits the method it brings to language acquisition. In this respect, the findings of this study should benefit teachers in comprehending what exactly to expect from blended learning if they use it as their method of instruction in language learning. In addition, they should learn of the negative outcomes associated with the concept, in order to better inform their decisions.

\section{Articles}

First, in a book of robotic education the authors described robots that have been used in various states to help in assisting elementary schools teaching process. This robot is not well recognized in Thailand. Identifying and conforming the quality dimensions from the perspectives of teacher is the main purpose of the study. 510 teachers were observed in elementary schools of Thailand. The result of Confirmatory Factor Analysis mentioned that a six-factor model to the observed data is fit. CFA construct discovered six robotic education quality dimensions. They are social interaction, the function of cognitive, method of teaching, the characteristics of pupil, principal features and also the content.

The second article is discussed with the blended learning in the areas of computing education. This paper provides the report that modern technology has provide depth and rigours with faculty with new approached to combine the model of active learning and increase student participation in the class. This current study is to response the question and provide with some solution with the other limitations and challenges against the previous studies. This contemporary research measures learning in a blended undergraduate management information systems course. It is obvious that the one class is fully conventional face-to-face class whereas the others approached are being one-third online.

The third article is relating with the latent model approached. The paper is promote a model to search and explore a topic of discussion via the latent semantic approach that named as Topics Finding Model. This approached is proposed a detail and complete steps to reveal the topic of discussion from a thread in a discussion forum. The proposed model consists of the algorithms on pre-processing text document, discussed with corpus classification and a topic. The model can be implemented in some various discussion forums and various interpreters of language with some few adjustments. The adjustments are regarding to stop-word removal list and stemming algorithm.

The fourth article is discussing with the implementation of Geogebra. According to this paper, It is presented the implications of GeoGebra that supported Micro Teaching Applications and TPACK game practices on the TPACK efficacy. The authors provided with the model of self-efficacy perception levels from all of the prospective mathematics teachers base on polygons. $2 \times 2$ factorial design that implemented and used on the paper. There are more than 88 prospective 
mathematics teachers that taken as participants in this experiments. Then, those teachers were divided randomly into 4 groups. According to the paper, they are G1, G2, G3, G4. Those teachers in G1 were participated in Micro Teaching Applications and Game-Based TPACK activities. The Mathematics teachers in G2 participated in GeoGebra Supported Micro Teaching Applications. Then Mathematics teachers in G3 group participated in Micro Teaching Applications. The last group, mathematics teachers in G4 group was participated in GeoGebra Supported Micro Teaching Applications and Game-Based TPACK activities.

The last article is relating with the measurement of the effects of robotics training on students' learning and creativity in physics. It investigated and enhanced the special effects of robotics training on students' creativity and learning physics. The experiment provided with Pre-test post-test base on quasiexperimental design that applied in the research design. It consists of one control group and one treatment group. 120 males and females from 11th grade are chosen to be the participants of the study. The uniqueness of this experiment is that the participants are studying at different schools in Tehran, Iran. Those participants are part of the robotic schools training programs in the educational year of 201617. The authors implemented multistage random cluster sampling that carried out as the sampling method of this research. The authors provide eight-session treatment period. The result after the sessions that the data were collected through adopted the Torrance Creativity Questionnaire. The questionnaires are including four dimensions, such as fluidity, flexibility, innovation, and detailed explanation. There are 60 items in the questionnaire. Some random test consists of 10 learning points, and a package of training on robotic constructs in physics. The authors implemented the covariance analysis to analyse the data. At the end of the experiment, the results showed that robotics training influence creativity and learning in physic among the participants.

\section{References}

Aguilar, J. (2012). Blended learning and the language teacher: A literature review. Colombian Applied Linguistics Journal, 14(2), 163-180.

Akkoyunlu, B., \& Soylu, M. Y. (2008). A study of students perceptions in a blended learning environment based on different learning styles. Educational Technology \& Society, 11 (1), 183-193. International Journal of Language and Linguistics Vol. 5, No. 4, December 2018. https://doi.org/10.30845/ij1l.v5n4 p657.

Bakir, D. A. (2013). Writing difficulties and new solutions: Blended learning as an approach to improve writing abilities. International Journal of Humanities and Social Science, 3(9), 254-266.

Barnes, M. (2017). Encouraging communication through the use of social media tools. In Multiculturism and Technology-Enhanced Language Learning, (IGI Global) 2017. Chapter, 1, 1-12.

Bijeikiene, V., Rasinskiene, S., \& Zutkiens, L. (2011). Teachers' attitudes towards the use of blended learning in general English classroom. Studies About Languages, 18, 122-127.

Cartner, H. (2009). Blended learning and the academic word lists. New Zealand Studies in Applied Linguistics, $15(2), 30-40$.

Coryell, J. E., \& Chlup, D. T. (2007). Implementing e-learning components with adult English language learners: Vital factors and lessons learned. Computer Assisted Language Learning, 20(3), 263-278.

Creswell. (2009). Research design: Qualitative, quantitative, and mixed methods approaches. Los Angeles: Sage Publications. 
Hwa, S., Weei, P., \& Len, L. (2012). The effects of blended learning approach through an interactive multimedia e-book on students achievement in learning Chinese as a second language at tertiary level. International Journal of Computer-Assisted Language Learning and Teaching, 2(1), 35-50.

Kintu, M. , Zhu, C., \& Kagambe, E. (2017). Blended learning effectiveness: The relationship between student characteristics, design features and outcomes. International Journal of Educational Technology in Higher Education. 14(7), https://doi.org/10.1186/s41239-017-0043-4.

Lo Bianco, J. (2010). Language policy and planning. In. N.H. Hornberger\& S.L. McKay (Eds.), Sociolinguistics and language education (pp. 143-174).

Sharma, P. (2010). Blended learning. ELT Journal, 64(4), 456-458.

Publisher's note Springer Nature remains neutral with regard to jurisdictional claims in published maps and institutional affiliations. 